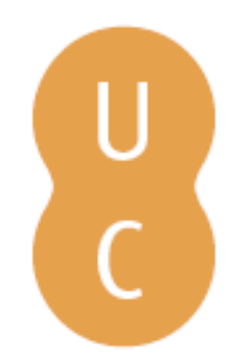

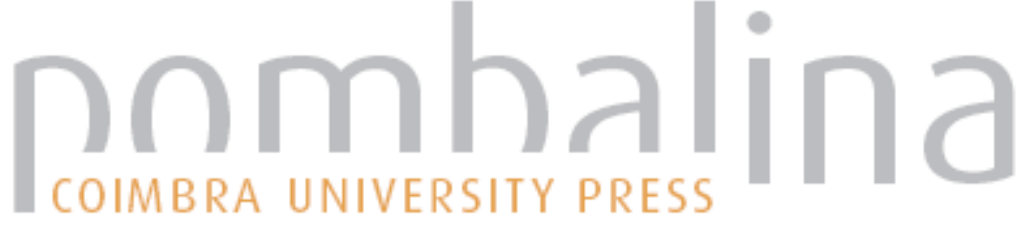

\section{A dimensão pedagógica da reforma de 1772: alguns aspectos}

Autor(es): $\quad$ Fonseca, Fernando Taveira da

Publicado por: Imprensa da Universidade de Coimbra

URL

persistente: URI:http://hdl.handle.net/10316.2/32748

DOI: $\quad$ DOI:http://dx.doi.org/10.14195/978-989-26-0373-5_2

Accessed : $\quad$ 26-Apr-2023 13:06:28

A navegação consulta e descarregamento dos títulos inseridos nas Bibliotecas Digitais UC Digitalis, UC Pombalina e UC Impactum, pressupõem a aceitação plena e sem reservas dos Termos e Condições de Uso destas Bibliotecas Digitais, disponíveis em https://digitalis.uc.pt/pt-pt/termos.

Conforme exposto nos referidos Termos e Condições de Uso, o descarregamento de títulos de acesso restrito requer uma licença válida de autorização devendo o utilizador aceder ao(s) documento(s) a partir de um endereço de IP da instituição detentora da supramencionada licença.

Ao utilizador é apenas permitido o descarregamento para uso pessoal, pelo que o emprego do(s) título(s) descarregado(s) para outro fim, designadamente comercial, carece de autorização do respetivo autor ou editor da obra.

Na medida em que todas as obras da UC Digitalis se encontram protegidas pelo Código do Direito de Autor e Direitos Conexos e demais legislação aplicável, toda a cópia, parcial ou total, deste documento, nos casos em que é legalmente admitida, deverá conter ou fazer-se acompanhar por este aviso.

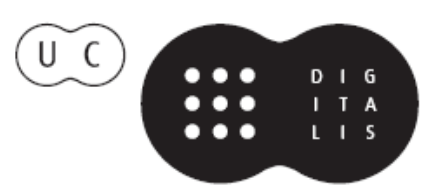




\section{ANA CRISTINA ARAÚJO \\ Coordenação}

\section{O Marquês de Pombal e a Universidade}

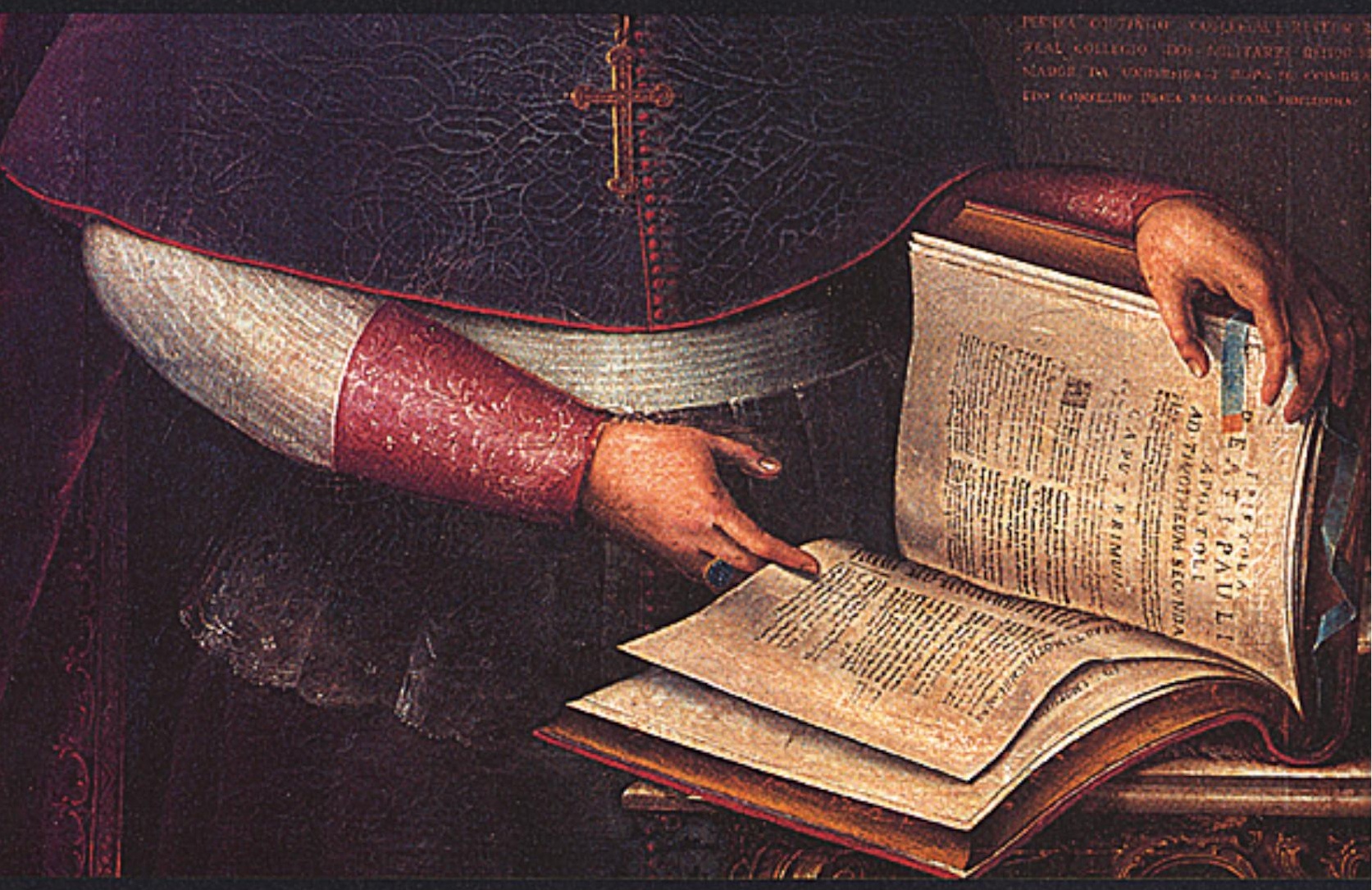

139. Coimbra - Imprensa da Universidade 
(Página deixada propositadamente em branco) 


\section{A Dimensão Pedagógica}

\section{da Reforma de 1772. Alguns Aspectos}

\section{ESTATUTOS}

UNIVERSI D A D E

D E $\mathrm{CO} / \mathrm{MBR} \mathrm{A}$ COMPILADOS DERATXO DA TMMEDTATA

E. SUPREMA INSPECGAO

DE ELREI D. JOSE I. NOSSO SENHOR

DE PROVIDLA J UN TATER ARIA CAEADA PELO MESMO SENHOA A RESTÂUiracío

DAS SCIENC:IAS, ARTFS LIIBERAES NESTES \# EINOS. TODOS SEUS DOMINIOS

POK SLA MAGESTADE

NA SUA LE OE A DE ACOSTO DISTE MUEKENTE ANNO.

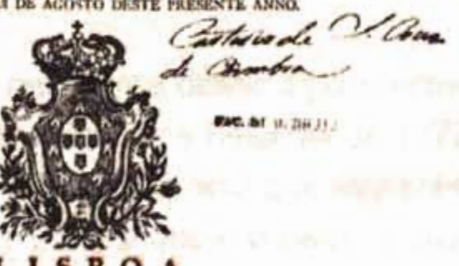

NA RRGIA OOFICINA TYPOGRAFICA.

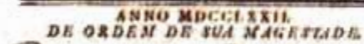

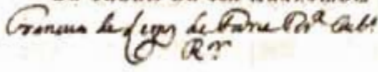


Estatutos da Universidade de Coimbra de 1772.

Biblioteca da Faculdade de Medicina da Universidade de Coimbra foto: Varela Pècurto 


\section{Fernando Taveira da Fonseca*}

\section{A DIMENSÃO PEDAGÓGICA DA REFORMA DE 1772 ALGUNS ASPECTOS}

1. A concretização de uma ideia de Universidade tem como consequência necessária o estabelecimento de normas reguladoras dos aspectos práticos do seu funcionamento. E se é certo que elas não podem ser dissociadas dos princípios que as fundamentam, é inegável o interesse em considerá-las de forma autónoma e sistemática, assim salientando a sua importância na economia global do processo de Reforma. Por outro lado, a sua comparação com as que definiam a situação anterior - ainda que de forma sumária - torna-se indispensável para determinar e pôr em evidência a novidade de que eram portadoras ou para, eventualmente, assinalar algumas linhas de continuidade.

Os tópicos segundo os quais se irá articular a presente exposição dizem respeito ao que se poderia definir, em sentido lato, como a dimensão pedagógica da Reforma de 1772: as condições de acesso, a organização do currículo, os processos de avaliação de conhecimentos, o estatuto e a condição dos professores.

Antes de os desenvolver, é pertinente definir a perspectiva que irá orientar o seu tratamento, que é a de entender a Reforma de 1772 na sua dimensão seminal e constitutiva. Daí a atenção especial que será prestada aos textos normativos ou programáticos. Fosse qual fosse o nível da sua efectiva aplicação ou a amplitude da sua recepção, elaborara-se formalmente um paradigma coerente, em oposição a outro legalmente vigente no período anterior, e esse dado é, por si só, da maior relevância, pelo efeito de legitimação que em si mesmo contém. Os reformadores, eles próprios, e o Marquês de Pombal em particular, pretenderam vincar esta perspectiva, ao definirem a sua obra como "nova fundação"; e toda a solenidade que rodeou a outorga dos Estatutos, em

- Facuidade de Letras da Universidade de Coimbra. Centro de História da Sociedade e da Cultura. 
exemplar manuscrito luxuosamente encadernado que ficou exposto à veneração geral ', a ordem dada para recolher e pôr fora de circulação todos os exemplares dos Estatutos Velhos, qualificados de perniciosos e entendidos como a consubstanciação de tudo o que de negativo se exprobara ao anterior sistema ${ }^{2}$, denotam a importância atribuída ao texto normativo e à sua força bloqueadora ${ }^{3}$ ou regeneradora.

2. Um dos traços que caracterizou o sistema de ensino em Portugal durante toda a Época Moderna foi o papel desempenhado pela Universidade de Coimbra que, não sendo a única com esse estatuto e designação (entre 1559 e 1759), detinha, contudo, a prerrogativa da concessão de qualificações profissionais reconhecidas, de forma exclusiva, no domínio do Direito, e, de modo privilegiado e maioritário, no da Medicina ${ }^{4}$. Este facto traduz-se em atracção continuada e crescente, manifestada no evoluir da frequência estudantil sempre em aumento até 1771 , sinal de que, no cômputo entre custos e vantagens inerentes à obtenção de um grau universitário, estas se revelavam

1 António de Vasconcelos, "Diário do que se passou em a cidade de Coimbra desde o dia 22 de Setembro de 1772. em que o Ill.mo e Ex.mo Senhor Marquês de Pombal entrou. até ao dia 24 de Outubro, em que partiu da ditta cidade", in Escritos Vários, $2^{\mathrm{a}}$ ed., Coimbra, Arquivo da Universidade, 1987, pp. 347-348.

2 Teófilo Braga, Histório da Universidode de Coimbra, Lisboa. Academia Real das Ciências. 1898, vol III, p. 440.

3 Uma ilustraçâo desta ideıa pode encontrar-se nos termos utilizados no despacho de 22 de Outubro de 1772, pelo qual o Marquês de Pombal dava instruçōes ao Reitor sobre a forma de organizar o Cartóno da Universidade: das colecções documentais que o deveriam constituir. a sexta seria a "Dos actos e juramentos extorquidos com sacrilego atrevimento e egual ignorancia aos Senhores Reis destes rennos como Protectores da Universıdade" (Teófilo Braga, História da Universidode, III, p. 441). O juramento do Protector impunha a este a obrigação de "guardar os estatutos, privilegios, libendades, usos e costumes" da Universidade. (Estatutos (1653), liv. I, tít. I. $\S 13$ e tít. $\mathbf{X} \S$ único).

4 Importa aqui deixar assinalado que, mesmo sendo a Universidade de Coimbra a única instituição que conferia graus em Medicina. a licença para curar poderia ser concedida pelo Físico-Mor a graduados por universidades estrangeiras ou a homens e mulheres que empiricamente tivessem adquirido algum saber na arte médica. A restriçāo que, em 1608, é colocada a esta jurisdição do Físico-Mor, limitando-a às localidades onde não houvesse graduados por Coimbra, vem acentuar a predominância desta instituição, embora não se possa falar, neste caso, de exclusividade absoluta (Maximiano Lemos, Histónia da Medicina em Portugal, $2^{\text {a }}$ ed., Lisboa, Publicaçōes D. Quixote/Ordem dos Médicos, 1991, vol I, pp. 158-161; Fernando Taveira da Fonseca, "A Medicina". in História da Universidade em Portugal, Coimbra-Lisboa, Universidade de Coimbra-Fundação Calouste Gulbenkian, 1997. vol. I, tomo II, pp. 837-838). 
maiores. Importa salientar ainda que a grande maioria de estudantes - e consequentemente de graduados - escolhia a via dos estudos jurídicos (87,3\% se tivermos em consideração o largo periodo que vai de 1577 a 1771) com clara predominância para o Direito Canónico (72\%, ficando 15,3\% para a faculdade de Leis).

$O$ acesso a qualquer destas duas faculdades era possivel desde que se obtivesse um certificado de aprovação no exame de Latim, efectuado no Colégio das $\operatorname{Artes}^{5}$. Condição mínima que não excluía que pudessem ser levados em conta outros estudos - filosóficos ou teológicos - feitos fora da Universidade. Esta constituía-se, deste modo, como lugar central de uma rede mais vasta de ensino que tinha como instituições imediatamente inferiores aqueles colégios aos quais tinha sido concedido o privilégio do "ano de Lógica" - o primeiro ano do curso filosófico, dedicado ao estudo da Lógica - cuja frequência era contabilizada como se de estudo na Universidade se tratasse 6 .

A possibilidade desta contabilização radicava na forma como estava organizado o próprio sistema de aprendizagem (a que dedicaremos alguma aten-

5 Feito com sucesso o exame de Latim, ao candidato era entregue um "passe" (designação que derivava da primeira palavra do pequeno bilhete assinado pelo Principal do Colégio das Artes: "Passe a $N$ certidão para ouvir Direito...). Com ele, o estudante obtınha certidão do Secretário da Universidade a qual, depois de autenticada com o selo do Colégio das Artes. permitia a efectivaç̧̧ão da matrícula. Nos "Conselhos para os novatos ocupparem o tempo das férias", insertos no Polito Métrico, dá-se conta da observância deste procedimento: "A primeira jornada, meu amigo Académico, que todos fazem lá em Coimbra, bem sabes que é para o Real Colégio das Artes, aonde se examinam para as ciências [...]. A segunda, não ignoras. é para a Secretaria a tirar certidão (Paito Métnco e correlotrva Macarrónea Louno-Portuguesa, nova edição de harmonia com a $4^{3}$, de 1792, Coimbra. Coimbra Editora, 1942, p. 180). A partir de 1716. embora contra a vontade dos jesuítas do Colégio das Artes, os estudantes filósofos que tivessem cursado no colégio dos oratorianos de Lisboa ficavam dispensados deste exame de Latim. a certıdão passada pelo Preferto da Congregação do Oratóno servia-thes de passe para se matricularem nas escolas maiores (Fernando Taveira da Fonseca. A Universidade de Coimbra (1700-1771). Estudo social e económico. Coimbra. Por Ordem da Universidade. 1995. p. 146)

6 Ao abrir do século XVIII, gozavam deste privilégio apenas alguns do colégios dos jesuítas: os de S. Antão (Lisboa), Porto, Braga e a Universıdade de Évora; no Brasıl, os da Baía, Rio de Janeiro e Pernambuco: a partir de 1716, também o de Santarém, Os oratorianos alcançaram, em 1708. para o seu colégio de Lisboa, a mesma prerrogativa que, posteriormente, se tomou extensiva ao Hospício das Necessidades (1745) e a todas as casas do Oratóno onde houvesse aulas públicas de Latim e Filosofia (1755). Em 1766, também os Reais Estudos de Mafra passaram a ter esta capacidade (Femando Taveira da Fonseca. A Universidade de Combra. pp. 146-147). 
ção mais adiante). Importa, de momento, referir que as condições de acesso às faculdades de Teologia e de Medicina eram diferentes: aos estudantes que se destinavam a uma ou outra era exigido que fossem bacharéis em Artes e que tivessem cursado o tempo necessário para se fazerem licenciados, ou seja, que tivessem ouvido todo o curso filosófico de três anos e meio, podendo, no quarto ano - chamado o ano da intrância - frequentar, de manhã, a faculdade maior a que se destinavam, concluindo, de tarde, o que restava do seu curso de Artes $^{7}$. Estabelecia-se, deste modo, uma íntima ligação entre o estudo da Filosofia, baseada estatutariamente no sistema aristotélico ${ }^{8}$, e estas duas faculdades maiores: as consequências eram relevantes. principalmente no que dizia respeito a Medicina. No caso concreto da Teologia, a existência de numerosos colégios de religiosos, que detinham a primazia na frequência desta faculdade ( $78 \%$ para o período de 1700 a 1771), matizava um pouco esta realidade: em muitos deles se professavam os estudos de Artes e os da mesma Teologia, vindo os seus membros, já em fase adiantada dos estudos, incorporar-se na Universidade para obterem os graus superiores de licenciado e doutor.

O panorama das condições de acesso à Universidade muda de forma substancial, com os Estatutos de 1772. Já alguns anos antes, aquando da reforma dos estudos "secundários", na sequência da expulsão dos jesuítas, se tentara valorizar o estudo do Grego e da Retórica como propedêutico dos cursos universitários: quanto ao Grego, estipulando que todos os que o tivessem estudado "com aproveitamento notorio" durante um ano fossem "preferidos em todos os concursos das quatro Faculdades de Theologia, Canones, Leys e Medicina", além de esse ano lhes ser levado em conta na faculdade que escolhessem; e no que dizia respeito à Retórica, exigindo que "depois de haver passado ano e meio" contado desde o estabelecimento do seu estudo público nos lugares em que tal se havia determinado - quatro professores em Lisboa, dois em cada uma das cidades de Coimbra, Évora e Porto, um em cada uma das outras cidades e vilas cabeças de comarca - ninguém fosse admitido a

7 Estatutos (1653), liv. III, tít. XXVI, in pr. e tít. XLIX, in pr. O grau de bacharel em Artes poderia obter-se desde que o estudante tivesse "ouvido toda a Logica, e cinco livros dos Physicos" (Ibidem, liv, III, tit. LX, $\S 3$ ); já o de licenciado pressupunha que ele apresentasse certidão "assinada pelo Principal e Regente, porque conste como ouvio aquelle curso todo de tres annos e seis mezes em que se leo" (tít. LXV, $\S 1$ ).

8 Estatutos (1653), liv. III, tít. LVIII, §2. 
matricular-se em alguma das quatro faculdades maiores sem ter sido aprovado no exame dessa disciplina, a efectuar "na mesma cidade de Coimbra, perante os Deputados nomeados pelo Director [Geral dos Estudos]" 9 .

As disposições estatutárias de 1772 vêm ampliar estas exigências. Antes de mais, pelo estabelecimento de idades mínimas de ingresso - para obviar, como explicitamente se afirma, a que se precipitassem os estudos preparatórios: assim é que ninguém poderia matricular-se em Teologia "sem contar dezoito annos de idade completos, e dahi para cima": o mesmo se aplicava a Medicina; para os cursos de Direito (Civil e Canónico) a idade mínima seria de dezasseis anos 10; já para Matemática se podia ingressar com quinze anos e para Filosofia, com catorze.

Estas idades devem entender-se em conjugação com as restantes condições de acesso e com os estudos de Matemática e Filosofia a que eram "obrigados" (formando uma categoria com esta designação, a par com as dos "ordinários" e a dos "voluntários") os estudantes das restantes faculdades. Com efeito, aos teólogos, para além do conhecimento das línguas latina, grega e hebraica, exigia-se que ouvissem "todas as Liçōes que se prescrevem para - Curso Filosofico" e que fizessem "todos os Actos que devem fazer os estudantes Filosofos até o de Licenciado inclusivamente" II. Por seu lado, os que se destinavam a Medicina, depois de estudarem Filosofia Racional e Moral durante um ano, teriam de frequentar "tres annos effectivos de Fysica e Mathematica" 12 para além de se apetrecharem com os conhecimentos das línguas latina e grega (ou, alternativamente, estudarem esta última disciplina na Universidade); e acrescentam os Estatutos que seria desejável que se instruíssem nas línguas vivas da Europa "principalmente na Ingleza, e Franceza, nas

9 António Alberto Banha de Andrade, A reforma pombalina dos estudos secundários (1759-1771), Coimbra, Por Ordem da Universidade, 1981, $2^{\circ}$ volume (Documentação), doc. I (Alvará de 28 de Junho de 1759). pp. 79-84.

10 A observação das idades efectivas dos estudantes que frequentavam as faculdades juridicas antes da reforma aponta para um intervalo que var dos dezoito aos vinte e cinco ou vinte e seis anos: mas o facto de não haver qualquer determinação quanto à idade mínima de ingresso na Universidade dava azo a que alguns estudantes efectivamente fizessem uma entrada precoce, nomeadamente nas faculdades junidicas (vide Fernando Taveira da Fonseca, A Universidade de Coimbra, pp. 270-276).

1 Estatutos da Universidade de Coimbra (1772), liv. I, tít. I. cap. III.

12 Estes cursos seriam preenchidos com duas cadeiras anuais, uma de cada faculdade: na de Matemática, sucessivamente, Geometria, Cálculo e Foronomia; na de Filosofia. História Natural, Física Experimental e Química (Estotutos (1772), liv. III, parte I. cap. II). 
quaes estam escritas, e se escrevem cada dia muitas Obras importantes de Medicina" 13. Para Direito, era exigido "um bom conhecimento da Lingua Latina, da Rethorica, da Logica, da Metafysica e da Ethica" e também do Grego. se o estudante provinha de localidade onde houvesse cadeira instituída ${ }^{14}$.

Mas juristas e teólogos viam ainda estas exigências ampliadas uma vez que uns e outros deveriam "estudar privativamente o Primeiro Anno do Curso Mathematico" no qual eram leccionados os Elementos de Geometria (que "são a Logica, praticada com a maior perfeição que he possivel ao entendimento humano") "como subsidio importante ao aproveitamento que devem ter no Estudo das suas respectivas faculdades"15. Deste modo, ao que se estipulava para os teólogos acrescentava-se a Geometria: os juristas, com um primeiro ano de Filosofia Racional e Moral e um segundo de História Natural na "Aula de Filosofia e a Geometria no Geral de Mathematica", teriam cumprido com o que thes era necessário para a matrícula.

É pertinente assinalar este carácter propedêutico que assumem, em dimensões variáveis conforme as faculdades de destino, os estudos que se professam nas de Matemática e Filosofia. Tanto como a sua elevação à categoria de faculdades autónomas - oferecendo uma graduação equivalente às restantes e destinando-se, em primeira mão, a formar profissionais nos respectivos ramos - vale esta sua inclusão como dimensionadoras da forma mentis que se postulava para os estudos que se pretendiam renovar. $O$ elogio da Matemática, que abre a parte dos Estatutos que lhe é dedicada (livro III, parte II) é secundado pelo enunciado de diversas vantagens de que auferirão os que, estudando-a, se encaminharem para o serviço régio, e é reiterado ainda quando se incentivam as inscrições de alunos voluntários nesta faculdade: as aulas ser-lhes-ão patentes sem quaisquer encargos e nelas serão admitidas "todas as pessoas que se quiserem instruir, de qualquer estado e condição que sejam"; os doutores das outras faculdades poderão aprendê-la da mesma maneira, ouvindo as liçōes do doutoral, dando deste modo, exemplo aos estu48 dantes, "para que se faça em toda a Nação o apreço destas Sciencias", com a vantagem suplementar, para os que assim procedessem, de serem preferidos nos concursos das suas faculdades. "Pelo contrario: Todos aquelles que,

\footnotetext{
13 Estotutos, liv. III, parte I. tít. I, cap. II.

14 Ibidem, Ivv. II, tit. I, cap. II e III.

is Ibidem, Irv. III, parte II, tit. II, cap. I.
} 
directa, ou indirectamente apartarem, ou dissuadirem a alguem dos Estudos Mathematicos; e com factos, ou palavras concorrerem, para que se não tenha huma idéa justa do lugar, e estimação, que merecem entre todos os conhecimentos humanos, não serão por Mim attendidos em Opposição alguma que façam às cadeiras das suas respectivas faculdades; e incorrerão no meu Real desagrado, como inimigos do progresso das Sciencias" 16.

É por isso, pela dignidade de que se revestem, que também para estas faculdades se ordena uma conveniente preparação: para os candidatos a Matemática, o Latim e, facultativamente, o Grego e as línguas vivas (Inglês e Fran(ês); obrigatoriamente, porém, um ano de Filosofia Moral e Racional, antes da matrícula e, juntamente com as disciplinas do primeiro ano, a História Natural e, com as do segundo ano, a Física Experimental; por sua vez, um curso completo de humanidades que proporcione a destreza necessária no uso do Latim (e do Grego, da mesma maneira que entende para as restantes faculdades) é a condiçăo indispensável para a inscrição em Filosofia, cujos alunos deverão igualmente, no seu segundo ano, ouvir as lições de Geometria no geral de Matemática.

Todo este conjunto de determinações obedece à intenção de tornar selectivo o acesso ao ensino superior que se quer reservado a um núcleo restrito de indivíduos que dêem garantias de idoneidade científica ${ }^{17}$. E também moral: por isso se exige aos candidatos ao curso de Teologia (que devem a ele ir preparados "com as disposições interiores da graça Dıvina") não somente a apresentação de folha corrida donde conste que não cometeram crimes, mas também uma atestatção de vito et moribus passada pelo respectivo prelado ${ }^{18}$. $E$ aos que pretendem inscrever-se em Direito não basta a prova de terem feito com sucesso os estudos preparatórios: os mestres que Ihos ministraram terão ainda de enviar ao Reitor da Universidade certiđão na qual se especifiquem as "circunstancias do talento para a vida literária". a sua propensão para o estudo e a diligência que haviam demonstrado, além

16 lbidem.

17 carácter selectivo do acesso aos novos cursos fica bem patente nas disposições. constantes do Edital de 5 de Outubro de 1772 e que dizıam respeito á transiçăo dos estudantes que ja tivessem cursado antenormente, claramente restritivas (vide Documentos da Reforma Pormbalina. publicados Por M. Lopes d'Almeida, Coimbra, Por Ordem da Univerșidade, 1937. vol. I, doc. XV. pp. 16-18).

18 Estotutos, liv. I, tít. I, cap. I 
de informarem sobre a "educação, probidade, genio, procedimento e costumes de cada hum dos mesmos Discipulos", bem como da "qualidade e bens dos seus pais"19.

3. É evidente que estas determinações sobre o acesso aos estudos superiores ganham sentido pleno apenas quando articuladas com as que definem - currículo, o tipo de aprendizagem a as formas de avaliação dos conhecimentos. Também nestes aspectos, o confronto com a norma e a prática anteriores esclarece o sentido e a amplitude da mudança.

Poderíamos caracterizar o sistema de aprendizagem vigente antes da Reforma pombalina - tal como é definido normativamente e independentemente de qualquer juízo de valor sobre o desempenho dos agentes que o ministravam - com os qualificativos de cumulativo, cíclico, "textual" e analítico.

O carácter cumulativo pode entender-se em dois sentidos. Por um lado, o estudante tinha que perfazer um certo tempo de estudo, medido em cursos, condição necessária para poder requerer ser avaliado e obter os seus graus. Os cursos - normalmente de oito meses, de Outubro a Maio, correspondendo ao ano lectivo - deveriam ser provados: a prova era apenas testemunhal, produzida por, pelo menos, dois condiscípulos da mesma faculdade sob juramento aos Santos Evangelhos ${ }^{20}$. Se tomarmos como exemplo as faculdades jurídicas - às quais, como vimos, acorria a grande maioria dos estudantes - verificamos que a primeira avaliação (as "conclusões" do quinto ano) se fazia apenas após cinco anos de frequência universitária. Esta norma, que a prática confirma, faz sentido no contexto do sistema em que se insere: todos os estudantes, fosse qual fosse o número de matrículas que tivessem efectuado (ou de anos que tivessem cursado) ouviam, cada ano, em cada cadeira, agrupados no mesmo geral, exactamente a mesma matéria: nem o facto de o primeiro ano dos cursos jurídicos ser dedicado ao estudo das cadeiras de Instituta infirma substancialmente esta característica geral. E se, ao

50 compulsarmos os Estatutos Velhos, temos a sensação de que, em Medicina, há uma distribuição de matérias pelos diferentes anos, será forçoso entendê-la como uma indicação aos professores da rotatividade do seu ensino e não como um ordenamento das etapas a serem percorridas pelo estudante. Efec-

\footnotetext{
19 ibidem. liv. II. tít. I, cap. II.

20 Estatutos(1653). liv. III, tít. I, $\$ 4$.
} 
tivamente a natureza cíclica do ensino conjuga-se com o seu carácter cumulativo (agora entendido na sua segunda acepção, a de acumulação de conhecimentos): o professor deveria fazer uma rotação de matérias ao longo de quatro anos ${ }^{21}$ (para algumas cadeiras de Medicina estipula-se um ciclo de cinco anos); o estudante só teria possibilidade de estar de posse de um conjunto significativo de conhecimentos, em cada cadeira, no final desse ciclo. Por isso os actos começam tarde, sucedendo-se depois a um ritmo mais acelerado. Também provavelmente por isso, o ciclo dos estudos é longo, mesmo se considerarmos apenas o tempo estatuído para obter um diploma que permitisse - exercício profissional e não já o necessário à consecução dos graus superiores de licenciado e doutor. Deste modo, a formatura, - que, para os juristas, era a qualificação necessária para poderem "usar de suas letras" ou seja, exercer uma actividade profissional - exigiria oito anos de estudo, dois deles cursados depois de haverem conseguido o grau de bacharel. É certo que concessões individuais ou abrangendo determinados grupos de estudantes ${ }^{22}$, as mercês de tempo, permitiam encurtar este periodo, sobretudo este último intervalo: mesmo assim, de 1700 a 1771, foi possivel verificar que a duração média do curso dos bacharéis formados nos dois Direitos era de 7,2 anos. Os médicos só poderiam exercer a clínica depois do acto de aprovação, que deveriam fazer no final do sexto ano: uma observação semelhante, para idêntico período permite afirmar que, em média, eles demoravam efectivamente seis anos.

Não será descabido encontrar neste carácter cumulativo do ensino uma das razões estruturais de um absentismo estudantil crónico que nenhuma medida - nem mesmo as matrículas incertas, instituídas após um levantamento dos estudantes contra a verificação da sua assiduidade, em 1660 conseguiu eliminar ou mesmo eficazmente debelar. Divertido por solicitações

21 Ibidem, liv. II, tít. XXIIII, § 3. Esta prescrição estatutária, dizendo respeito à determinação das matérias para cada ano lectivo, pressupōe que, nessa escolha, fosse atendida, no que dizia resperto às cadeiras grandes, a vontade dos estudantes (ad vota audientium). Os registos universitários não assinalam qualquer escolha deste tipo ao longo de todo o século XVIII (com excepção de um ano, por expressa ordem régia), pelo que o costume se terá perdido, ficando ao arbítrio do professor escolher as matérias a leccionar.

22 Como acontecia com os estudantes ultramarinos aos quais, em compensação dos quinze dias de tolerância de que gozavam os reinóis para se poderem matricular, em Outubro e em Maio (o que perfazia um mês em cada um dos oito anos do curso), era concedida uma mercê de tempo de um ano lectivo (curso de oito meses). 
várias, o estudante, ontem como hoje, preocupa-se seriamente com o estudo apenas quando sente $o$ aguilhão da obrigatoriedade de prestar contas da sua aprendizagem (como confessa o quartanista do Palito Métrico, denominado "candieiro" porque, mesmo que não luza como sábio, ao menos, "com a claridade do conhecimento da própria vida", se dá conta de quão necessário é estudar, uma vez que os actos estão perto ${ }^{23}$ ).

A base para este tipo de ensino eram os "textos". Poderíamos sinteticamente defini-los como repositórios ou tesouros de temas, de questōes. de soluções e de autoridades: quer se tratasse das compilações do direito civil romano e do direito eclesiástico; fossem eles a Biblia ou as sumas escolásticas (as de Pedro Lombardo e de S. Tomás de Aquino, em primeiro plano): assumindo ainda a forma de tratados das primitivas grandes autoridades da Medicina greco-romana e árabe (Hipócrates, Galeno, Avicena, Razi), eram encarados como fontes, cânon aceite dos conhecimentos cientificos seguros, confirmados e úteis; o trabalho do professor consubstanciava-se na sua interpretação e na sua ampliação pelo comentário. Estas duas operações constituiam a base da "leitura": "ler" era precisamente interpretar e comentar. dando a maior parte das vezes a essa explicação (e entendendo aqui o conceito de explicar na sua dimensão etimológica de "desdobrar") a forma da disputa, encabeçando cada problema ou questão pela partícula dubitativa utrum, procurando a solução verdadeira como refutação das razões de duvidar. Esta forma é ainda visivel nas apostilas que resultavam do ditado que o professor fazia depois da "leitura".

O carácter analítico do ensino vinha-lhe da sua própria base: era possível separar elementos suficientemente autónomos dos "textos" e tratá-los individualmente, uma vez que a constituição daqueles obedecia essencialmente a uma lógica de justaposição 24: e a atenção ao parcelar, à peça do conjunto cuja percepção global só se alcançava no final do processo de aprendizagem, excluía a intenção de progresso gradual e de passagem do mais simples ao mais complexo.

23 Palito Métrico. p. 191.

${ }_{24} \mathrm{Um}$ dos exemplos mais flagrantes pode ser encontrado na Summa Theologica de S. Tomás de Aquino. As grandes divisões em partes (que são conjuntos temáticos vastos) englobam numerosas quaestiones que, por sua vez, se subdividem em artigos. Estes são unidades mínimas e autónomas: cada um apresenta um problema, as razōes contra e a favor de uma determinada conclusăo, a formulação explícita dessa mesma conclusão e a refutaçăo das opiniōes opostas. 
Foi precisamente essa intenção que, em oposição declarada ao sistema e à prática anteriores, presidiu à instauração pelos Estatutos da Reforma de 1772 de um método que é neles definido como de sintético-demonstrativo-compendiário que deveria ser seguido "uniforme e invariavelmente por todos os professores" nas lições públicas, "dando-se nellas primeiro que tudo as definições e as divisões das Matérias, que mais se ajustarem às Regras da boa Dialectica: passando-se logo aos primeiros principios e preceitos geraes mais simplices, e mais faceis de se entenderem: E procedendo-se delles para as Conclusōes mais particulares, formadas da combinação de maior numero de ideas, e por isso mais complicadas, e sublimes, e de intelligencia mais difficultosa". Este conjunto de princípios a que o legislador dá esta formulação quando trata do ordenamento dos cursos jurídicos mas cujo sentido geral percorre insistentemente todo o texto dos Estatutos, tem como consequência primeira a determinação de que "na prática, e execução do mesmo Methodo Synthetico, se siga, e abrace tão sómente o Caminho Compendiario" devendo os professores "ensinar [...] a Jurisprudencia por Compendios breves, claros e bem ordenados" 25 . Terceiro vector desta nova metodologia que se pretendia instaurar era o do seu carácter demonstrativo e científico, que poderemos entender primeiramente como sequela natural do espirito geométrico ("o espírito de exactidão, de precisão e de ordem, de que muito necessitam os Juristas, que hão de manejar a balança da Justiça, para poderem trazer o fiel della sempre constante, e firme no ponto da rectidão") ; e depois como contraposição à omnipresença anterior da disputa e da casuística.

Não que a perspectiva analítica fosse de todo posta de parte: pelo contrário, ela era valorizada, como instrumento fundamental para a interpretação e boa aplicação das leis, desde que entendida como coroamento de um processo que. partindo da aquisição das noções gerais e dos princípios, só depois enveredasse pelas aplicações particulares: "depois de bem sabidos os Principios, não ha occupação, nem exercício, que tanto possa servir aos Estudantes de ensaio para a applicação das Leis aos factos que thes occorrerem no foro, como he o uso e a prática da analyse dos Textos" 26.

É esta perspectiva geral que, com matizes próprios, se aplica às restantes faculdades. Na Teologia, a sua parte sistemática - "que ensina todas as doutri-

\footnotetext{
25 Estatutos, liv. II, tít. III, cap. I.

26 Ibidem.
} 
nas e verdades, reduzidas a hum unico corpo" - deveria estar de tal modo ordenada que primeiro se aprendessem as materias mais simples que dão luz para as outras, "e depois dellas sabidas se passe às mais sublimes, e que mais necessitam das precedentes para se poderem bem comprehender". Quanto à sua outra grande vertente, a exegética, que "hé verdadeiramente a primeira, e a principal de todas as Disciplinas Theologicas", a crítica que se faz à situação anterior ("tem sido a mesma Exegetica tratada com grande negligencia nas Escolas de Theologia") reporta-se principalmente à falta de "noções prévias" necessárias para a "boa intelligencia das Escrituras", à ausência do ensino das "Regras da Hermenêutica Sagrada" assim como dos "subsidios que ella requer para a verdadeira e sólida interpretação" 27.

A esta insistência no carácter gradativo da aprendizagem e da sua fundamentação em princípios gerais orientadores acrescenta-se um dado importante que ganha particular relevo no caso da Medicina: a adopção de uma atitude empírico-racional (que implica a rejeição quer do puro empiricismo quer do racionalismo extreme), com a afirmação de que "não há meio mais seguro para adiantar a Medicina do que comparar perpetuamente os resultados da razão e da experiência"; o que leva a concluir que a Medicina teórica - excluindo previamente qualquer sistema antigo ou moderno "a cujo serviço se sacrifiquem as observações", e também o sincretismo e o eclecticismo constaria "unicamente [...] das verdades de facto que forem provadas por hum numero sufficiente de experiencias decisivas". Este apelo à experiência tem a sua sequência natural na condenação do "divorcio" entre Medicina e Cirurgia que havia sido "mais do que todas as outras causas prejudicial aos progressos da Arte de curar e funesto à vida dos homens; não sendo possivel que seja bom Medico quem não for ao mesmo tempo Cirurgião, e reciprocamente" 28. A determinação para que o estudo da Cirurgia prática e especulativa acompanhasse sempre o da Medicina e para que, de futuro, nas cartas de curso constasse a dupla qualidade de médico e cirurgião daquele que se gra-

54 duava, rompia com um preconceito generalizado que depreciava a actividade do cirurgião e que considerava indignas do médico as operações manuais que aquele devia executar.

\footnotetext{
27 Ibidem, Iiv. I, tít. II, cap. II (para as expressōes entre aspas).

28 Ibidem, liv. III. parte I, tít. II, cap. II (para as expressões entre aspas).
} 
A tradução desta axiomática na organização do currículo dos estudos de cada faculdade faz-se por uma minuciosa ordenação das cadeiras ao longo dos anos, agora considerados não como meras unidades acumuláveis mas como sucessivos e não permutáveis degraus de um percurso hierarquizado. Não sendo possível dar aqui conta, ainda que sumária, desta distribuição das cadeiras pelos diversos anos, nas diferentes faculdades, não poderemos deixar de assinalar a extrema minúcia com que a ordem das matérias é organizada. a indicação precisa dos conteúdos que devem ser ministrados e as doutrinas que devem ser seguidas (nomeadamente em pontos sensíveis como, por exemplo, a relação entre os poderes civil e eclesiástico). $O$ critério de disposição cronológica das cadeiras de forma gradativa, em termos de importância e de complexidade, vem expressamente afirmado: "a precedencia de cada huma dellas se regulará pella ordem das Disciplinas do Curso da Faculdade a que pertencerem: sendo sempre inferiores as das disciplinas que primeiro se deverem ouvir: principiando-se consequentemente pelas subsidiarias; subindo-se destas para as Elementares; das Elementares para as Syntheticas; e passando-se das Syntheticas para as Analyticas ${ }^{29}$.

Em termos práticos, e tomando sempre como primeira referência as faculdades jurídicas, esta sequência implica que, a um ritmo diário de cinco horas de lição (uma para cada cadeira), sejam necessários três gerais para a leccionação das dezasseis cadeiras (uma comum, a de Direito Natural, sete de Cânones e oito de Leis) criadas para ambos os cursos, cujos alunos, nos dois primeiros anos, frequentavam as mesmas disciplinas, só depois se especializando no respectivo ramo jurídico. E se bem que os estudantes sejam compelidos a ouvir cada dia todas as cinco horas de lição - o que pressupōe que irão frequentar cadeiras que não são do seu ano - o dado mais relevante a ter em conta, neste caso, é a obrigatoriedade de eles fazerem exame das disciplinas correspondentes a esse ano. $O$ insucesso no exame tinha como consequência que não poderiam transitar para 0 ano seguinte, ficando "manentes" até alcançarem a preparação suficiente para a superação dessas provas.

Esta era uma das novidades mais interessantes do novo ordenamento académico que tem de ser entendida no contexto mais amplo do sistema de avaliação de conhecimentos. Conforme já assinalámos, a norma e a prática anteriores não implicavam a "passagem de ano": mas não era esta a única

\footnotetext{
29 Estotutos. liv. II, tit. II, cap. V. $\$ 6$
} 
diferença. Todo o sistema de avaliação se baseava, nessa altura, em dois tipos provas: as conclusões e as lições de ponto. As primeiras eram elaboradas por escrito mas destinavam-se à disputa oral, facto que obrigava à sua publicitação antecipada, de modo a que os arguentes se pudessem preparar; as lições de ponto eram exposições orais sobre passagens dos textos (pontos ${ }^{30}$ ), tiradas à sorte com uma antecedência que nunca ultrapassava um dia e meio. Umas e outras faziam sobretudo apelo à memorização e à capacidade de expressão ${ }^{31}$.

O sistema implantado pelos Estatutos de 1772 difere substancialmente: desde logo porque se fundamenta em uma constante verificação dos conhecimentos adquiridos. Na verdade, os "exercícios vocais" quotidianos, colocados na parte final de cada lição, destinavam-se a testar a assimilação do que havia sido ensinado na anterior; por sua vez, recapitulavam-se cada semana e cada mês, de forma semelhante, as matérias dadas nesses períodos, oralmente ou por escrito. Ao professor era pedido que conhecesse nominalmente todos os seus estudantes: para facilitar este conhecimento, competia- the destinar a cada um deles o seu lugar na sala, a partir de um rol elaborado pelo bedel de acordo com a ordem das matrículas. Esta distribução de lugares constava de um mapa permanentemente afixado e não poderia ser alterada pelos estudantes mesmo quando alguns dos seus colegas não compareciam, deixando assim vagos os lugares dos ausentes.

É evidente a intenção de verificar a assiduidade. reforçada pela determinação de "apontar" os que faltassem, para o que se designavam "apontadores" entre os mesmos estudantes. A rotatividade aleatória - a arbítrio do professor - dos que deveriam responder, ou, nos exercícios semanais e mensais, a escoIha de defendentes e arguentes por sorteio ("para que todos cuidem não

30 Sendo embora destinadas a exposição oral, algumas liçōes de ponto chegaram até nós na sua forma escrita, com certeza resultante da rápıda preparação que exigiria, pelo menos, a ordenaçāo dos tópicos que inam ser desenvolvidos (no caso do exame privado, por exemplo, pelo espaço de uma hora). Trata-se de pequenos incisos, seleccionados de agrupamentos mais amplos, o que permite ao candidato alguma liberdade de escolha. Uma fórmula estereotipada dá-nos conta deste tipo de selecção: Sequitur explicandus [indicação do autor e do texto], ad illa formalia verba [indicação do ponto] (Fernando Taveira da Fonseca. "A Teologia". in Históna da Universidade em Portugal, vol. I, tomo II, pp. 790-791)

31 Que eram criténos básicos de aferiçāo da competência meșmo para aqueles que se destinavarn ao professorado, conforme é patente nos pareceres elaborados aquando dos concursos para as cadeiras (Fernando Taveira da Fonseca. A Universidade de Coimbra, pp. 456-461) 
só em residirem, e frequentarem os Geraes, mas tambem em estarem preparados, com receio de poder cahir nelles a sorte" ${ }^{32}$ ) reforça esta tendência fiscalizadora e pretende colmatar as deficiências estruturais do sistema antecedente.

A menor duração dos cursos era assim contrabalançada por uma maior exigência e intensidade do estudo: de facto, o modelo adoptado foi o de, nas faculdades já antes existentes, reservar cinco anos para a aquisição da qualificação profissional básica (formatura), deixando para o sexto ano (que, por isso, se chamava ano da graduação) um suplemento de estudo e os actos necessários à aquisição dos graus superiores de licenciado e doutor. Nas faculdades recém-criadas de Matemática e Filosofia, a formatura obtinha-se no final do quarto ano, ficando o ano da graduação a ser o quinto.

O modelo de avaliação combinava o método "socrático ou dialogístico" com o amplo uso da dissertação. $O$ interrogatório, feito por diversos examinadores pelos quais se distribuíam as diferentes matérias, previamente sorteadas dentre as que haviam sido leccionadas, deveria ser utilizado em exclusivo nos exames dos dois primeiros anos que constituiam o tronco comum dos cursos jurídicos, assim como nos do primeiro ano dos teólogos ${ }^{33}$. Mas constituiria sempre parte essencial de todos os exames. Mantinha-se assim o predomínio da oralidade que se reforçava pela obrigatoriedade de cada examinando iniciar a sua prova (excepto nos casos acima mencionados) recitando de memória uma dissertação que havia composto previamente sobre um tema também sorteado.

As particularidades deste sistema, conforme as faculdades e os anos a que os exames diziam respeito ${ }^{34}$, nāo infirmam a sua coerência global: as determinações estatutárias insistem na pluralidade dos interrogatórios, de modo a testar a assimilação das diversas matérias leccionadas, sem ultrapassar, porém, o conteúdo dos compêndios; na autoria individual das dissertações

32 Estotutos, liv. I, tít. IV. cap. I, $\$ 34$

33 Para permitir uma maior brevidade, estes exames poderiam ser fertos por turmas, cuja composição e número competia à Congregação da respectiva faculdade determinar.

34 Tais particularidades diziam essencialmente respeito ao exercicio da presidência em cada um dos exames (que cabia normalmente ao professor que leccionava a matéria objecto do exame. o qual não interrogava); ao número de examinadores (geralmente três mas que poderiam subır a quatro no exame de formatura); à duração da dissertação ("brevíssıma". ou seja, não ultrapassando um quarto de hora, na quase totalidade das provas, mas demorando meia hora nos actos de formatura). Cfr. Estotutos. passim. 
- condenando o costume anterior das ajudas que, para os actos, eram dadas aos examinandos; no rigor da avaliação, estabelecendo um limite de três reprovações como máximo, após o qual o candidato não poderia mais apresentar-se a provas para obter o seu grau de bacharel ou a formatura.

De especial cuidado se revestia a organização deste último acto: colocado no final do quinto ano (no qual eram leccionadas as cadeiras analíticas e, em Medicina, exclusivamente dedicado à prática) ou constituindo um exame independente no termo do quarto ano nas faculdades de Matemática e de Filosofia, nele se deveriam explorar não só as temáticas próprias desse ano. mas igualmente recapitular todos os conteúdos dos anteriores, assim se constituindo como teste de uma maturidade global que os exames parcelares não teriam podido comprovar cabalmente: a maior duração da dissertação inicial, o número acrescido de examinadores (quatro, argumentando cada um pelo tempo de quinze minutos), a distribuição, por cada um deles, de diferentes assuntos para que não coincidissem nos seus interrogatórios, a recomendação para que, a partir do tema sorteado, se explorassem todas as matérias conexas (quer tivessem sido ministradas nas cadeiras subsidiárias, quer nas elementares e sintéticas) são o corolário prático de um princípio enunciado de forma recorrente: o da necessidade de se explorarem, "com muito cuidado" as aptidões do examinando para as actividades práticas que, obtida a formatura, poderia legalmente exercer sem necessidade de qualquer outra prova ou atestação, o da obrigação de os professores não usarem da "indulgência de approvarem os que na sua consciencia" não julgassem capazes para elas.

Neste contexto. merece uma atenção particular o modo de avaliação na faculdade de Medicina, precisamente por causa da componente prática que se pretende o caracterize. Logo nos exames do primeiro ano, juntamente com a teórica de Matéria Médica, os estudantes eram obrigados a uma prova prática de operações químicas e de preparações farmacêuticas: agrupados em turmas, se o seu número o justificasse, na sala do Dispensatório, os que tives-

58 sem superado a teórica deveriam executar individualmente uma "operação" cujo resultado apresentavam à apreciação do corpo dos docentes (catedráticos e substitutos) aí reunido; o esquema repetia-se no segundo ano (agora com Anatomia, ataduras, partos e operações cirúrgicas "servindo-se para isso de corpos artificiais na falta de cadaveres" ${ }^{35}$ ). Mas o ponto culminante de

35 Estotutos, liv. III, parte I, tít. V. cap. II, §7. 
todo este processo era o exame de formatura que consistia exclusivamente no exercício da prática clínica (depois de um ano que a ela tinha sido totalmente dedicado) no hospital, observado por todos os lentes da faculdade, por um período que ia desde o dia dez de Julho até ao dia trinta do mesmo mês: não eram feitas ao examinando nem perguntas nem observações; se o lente examinador discordava das decisões do examinando em matéria de prescrição, comunicava em segredo aos enfermeiros a que lhe parecia correcta. Todo o juízo se reservava para a tarde do dia trinta de Julho, no qual, em presença do Reitor, os professores votavam: e eram suficientes dois votos negativos para que o bacharel reprovasse, sendo-lhe facultada uma segunda oportunidade no ano seguinte. Uma terceira reprovação, dois anos depois, vedava-lhe de todo a possibilidade de obter a formatura e, consequentemente, de exercer a clínica.

Do mesmo modo que o tempo necessário à obtenção de uma qualificação profissional, foi uniformizado o percurso posterior para a obtenção dos graus de licenciado e doutor: mais um ano de estudo, sem disciplinas especificas, mas apenas destinado ao aprofundamento de matérias já versadas ${ }^{36}$, e no final, dois actos, o de repetição ou conclusões magnas e o exame privado. Para além de se uniformizar, simplificava-se: na realidade, antes da Reforma, as exigências para os juristas não coincidiam com as de teólogos e médicos e o tempo que devia mediar entre a formatura (ou a aprovação dos médicos) e o exame privado era também muito diferente (quatro cursos para os médicos, dois para os teólogos, um apenas pará os juristas); por outro lado, eram então mais numerosos os actos necessários para se poder aceder a este último exame (privado) ${ }^{37}$.

Mantinham-se contudo, os dois momentos que já anteriormente se definiam como fundamentais. Para os juristas, a repetição (que agora conserva esta designação ou, alternativamente, a de conclusões magnas) era, na expres-

36 Os teólogos deveriam frequentar as duas cadeiras de Escritura que haviam já ouvido no quinto ano; do mesmo modo, os juristas repetiriam as cadeiras analíticas, também do quinto ano; já aos médicos se pretendia dar um complemento teórico com as disciplinas do terceiro e quarto anos: da mesma forma. matemáticos e filósofos aperfeiçoariam as matérias dos terceiro e quarto anos.

37 Para uma descriçāo mais pormenorizada do conjunto de actos que deveriam ser feitos entre a formatura ou aprovaçăo e o exame privado, ver Fernando Taveira da Fonseca. A Universidade de Coimbra. pp. 57-60. 
são dos Estotutos Velhos, "o mais grave que estas duas faculdades têm: em que se hão de dizer todas as cousas do Direito, mui escolhidas e apuradas, assi na essencia e verdade. como na ordem e allegação: porque he acto sem ponto que se tem no livro e texto que cada hum quer: e se vai ordenando por todo o tempo do estudo" 38. Mais prolixamente, os de 1772, repetem as mesmas ideias ${ }^{39}$. A novidade estava, mais uma vez, na introdução de uma dissertação - cujo tema seria fixado no início do ano pela Congregação da faculdade que precedia a discussão dos pontos das diversas matérias que formavam o conteúdo das conclusões, e na extensão deste acto a todas as faculdades como pródromo necessário à entrada em exame privado.

Este continuava a ser o culminar de todas as provas académicas segundo um figurino que só se modificava em alguns pormenores: o intervalo entre a tiragem dos pontos e a efectivação das provas alargava-se de dois para quatro dias; diminuía-se a duração das liçōes (a primeira teria três quartos de hora e a segunda meia hora, em vez das duas horas que, pela norma anterior. elas deveriam perfazer) mas aumentava-se de quatro para seis o número de argumentatntes, a cada um dos quais era concedida meia hora; eliminava-se a dupla votação, por pontos, para a penitência, e por AA e RR, uma vez que o candidato reprovado ficava necessariamente penitenciado a cursar mais um ano, embora the fosse permitido submeter-se a provas por mais duas vezes.

De resto. o cotejo das prescrições que regulamentavam o exame privado em uns e outros Estotutos, revela um paralelismo que demonstra que os Velhos serviram, neste aspecto, de suporte aos da Reforma. Poderia dar-se como exemplo a terminologia utilizada quando se define a obrigatoriedade de examinar a idoneidade moral dos candidatos teólogos, muito semelhante

38 Estatutos(1653), liv. III, tít. XLVI, in pr.

39 Como poderemos exemplificar com o que eles referem a resperto dos juristas (Iiv. II. tí. IX, cap. VII, § 5): "A muita gravidade deste acto, a forma com que elle se deve fazer, e o muito que se devem esmerar os que o fizerem, para que tudo o que nelle disserem seja o mais bem escolhido e apurado, assim na substancia das Theses e Conclusões, na importancia das materias, na solıdez das doutrinas, na selecção das opiniōes, no uso da Critica e no bom gosto da Jurisprudencia; como tambem nos accidentes com que as mesmas Theses e Doutrinas se devem sustentar e expôr, serão sempre impreteriveis no mesmo acto. Porque nelle não serão já as materias e conclusōes que se offerecerem à disputa subministradas pelo accaso das sortes para se defenderem quasi de repente; mas sim pello contrano aquellas que os Repetentes quizerem eleger, depois de se terem preparado para ellas com estudo vagaroso e premeditado por todo o tempo do Curso Juridico [...." 
em um e outro texto normativo ${ }^{40}$. Mantinha-se, deste modo - e reforçava-se - a dimensão ética que deveria andar associada à capacidade científica. Não podemos, de facto, esquecer a expectativa interessada que rodeava a concessão dos graus superiores, expressamente afirmada através de uma teoria do carácter instrumental da Universidade face aos "Supremos Poderes Espiritual e Temporal":

Sendo os ditos Gráos instituidos para testemunho público, e significação authentica da habilitaçăo para o Magısterio: Trazendo a si annexa a licença de ensinar, que notoriamente requer huma sabedoria mais alta, e muito superior à que basta para a Collação dos Gráos inferiores: Costumando os mesmos Gráos servir de regra a ambos os Supremos Poderes, Espiritual e Temporal, para se governarem e regerem por elles no provimento das Dignidades, Beneficios, Ministerios e Empregos, que pela sua maior gravidade e importancia só se costumam conferir aos que com elles se acham graduados, na supposição de serem elles os mais sabios e idoneos para bem servirem à Igreja e ao Estado: Contendo em si os testemunhos de Sabedoria dirigidos pelas Universidades immediatamente aos ditos Supremos Poderes. para por meio delles calcularem melhor o merecimento dos sujertos que mais convem ao bem público se provejam nos referidos empregos: $E$ sendo este verdadeiramente o unico fim, pelo qual os mesmos Supremos Poderes concedêram ás Universidades a faculdade de conferir os ditos Gráos: A todos se faz manifesto.e patente, que a extemporanea collação delles aos Bacahareis, que apenas acabam de formar-se [...] seria ultimamente de grande prejuizo, e das mais terriveis consequencias para o bem público da Igreja e dos Estados 41 .

40 Dizem os Estotutos Velhos (liv. III, tit. XXXVIII, § I): farseha outrosi, antes de se asinarem os dias, o exame de vito et moribus et sufficientra, conferindoo [a Congregaçāo] entre si: e achandoos deshonestos, dissolutos, brigosos ou escandalosos, ou notoriamente insufficientes, os não admittiräo ou thes diffirirão a tal appresentação, como melhor thes parecer". Por sua vez. os Estatutos de 1772 (liv. I, tít. IV, cap. VI. §̧63) ordenam: "passará a mesma Congregação ao Exame de vito, et moribus de cada um dos Examinandos. [...] E achando que ha alguns escandalosos, dissolutos, rixosos ou deshonestos, os não admittirão; ou thes defirirão à tal apresenta̧̧ão, como melhor thes parecer". Não é fácil determinar qual o alcance do termo "sufficientia" que desaparece nos Estatutos da Reforma: muito provaveimente não teria a ver com aspectos de carácter cientifico ou mesmo ético, mas sim com qualidades físicas ou sociais e, por contraDartıda, a ausência de "defeitos" da mesma natureza que se julgassem incompativeis com a honra académica a que o exame privado abria as portas. A este propósto, é muito interessante atentar na resistência que a universidade opôs a conceder o doutoramento a candidatos mulatos e na argumentaçāo que a fundamentava (cfr. Femando Taveira da Fonseca, $A$ universdade de Combra, pp. 255-260).

41 Estatutos, liv. I, tit. IV, cap. VI, § 2. 
4. $O$ quadro que nos propusemos esboçar incluiu ainda um traço que parece indispensável: na dualidade que constitui a relação pedagógica, importa atender ao estatuto e condição dos professores. Uma das medidas imediatamente postas em prática pelo Marquês Reformador foi precisamente a profunda renovação nos quadros docentes da Universidade, removendo por meio da concessão de jubilações - a que se juntou, em três casos, a benesse de uma conezia doutoral - os que ainda restavam dos antigos professores ${ }^{42}$, e garantindo aos condutários de Medicina a continuação do pagamento das pensões que até aí recebiam ${ }^{43}$. Aos providos de novo que ainda não possuíam a láurea doutoral foi-lhes concedido o grau, assim ficando de imediato regularizada a sua situação como docentes.

Não se tratou, contudo, apenas de renovar o pessoal: modificou-se igualmente a estrutura do corpo de professores e redefiniram-se as suas funções. Antes de mais, pela criação da figura do lente substituto, como categoria permanente e afecto a uma cadeira ou cadeiras específicas, com a finalidade explícita de garantir a regularidade do processo lectivo e de avaliação ${ }^{44}$. $\mathrm{Na}$ realidade, a norma e a prática anteriores de organizar as substituições deixavam uma boa parte da iniciativa ao próprio lente proprietário quando este ficava impedido por doença, pelo que elas se faziam, muitas das vezes, por uma ligação pessoal de confiança entre este e o substituto; por outro lado,

42 Sem que nenhum documento o declare explicitamente, parece ter havido uma actuação consciente por parte dos órgãos centrais no sentido de progressivamente esvaziar o corpo docente de Coimbra. $O$ sintoma mais evidente desta atitude - para além de outros que seria longo enumerar - poderá ser o facto de nenhum provimento ter resultado dos concursos que se efectuaram, em 1765. nas faculdades de Teologia, Cânones e Leis (vide, para um tratamento mais pormenorizado. Fernando Taveira da Fonseca, A universidade de Coimbra, pp. 442-446).

43 Conforme já afirmei em outro lugar (A universidade de Coimbro. pp. 445-446), esta profunda renovação não se saldou em total ruptura: dois dos novos lentes de Medicina haviam sido condutários, outros haviam concluído a sua formação em Coimbra. Nas restantes faculdades, com especial destaque para a de Leis, alguns daqueles doutores que haviam feito substituiçōes no período anterior, são agora nomeados como proprietários ou substitutos (Ver Mário Alberto Nunes Costa, Documentos para a histónia da universidade de Combra, Coimbra, Por Ordem da Universidade, 1961, vol. II. docs. DLXXXV a DXCIV e DXCIX, pp. 287-294: Documentos da Reforma, vol. I, docs. IV.V.VI, XII,XIII e XIV, pp. 6-9 e 14-16).

44 Este cuidado leva a que. para além desta categoria de substitutos, se determine que. em cada ano lectivo sejam designados outros substitutos eventuais, entre os opositores, obrigados à permanência na universidade, os quais servinam para colmatar as ausências simultâneas de proprietários e substitutos. 
a determinação de que, em caso de ausência até dois meses, o Conselho, proveria a substituição no lente da cadeira imediatamente inferior (gerando também uma deslocação temporária nas restantes) era prática corrente: tudo isto se traduzia em efectiva irregularidade das lições, embora se mantivesse uma continuidade material. Com a Reforma, os substitutos fazem parte do quadro normal, e constam da "folha académica" que estabelece os ordenados de lentes e oficiais, promulgada em 22 de Outubro de 1772 45. E formando uma categoria distinta, bem visível de resto pela diferença das remunerações auferidas, gozavam de igual direito ao preenchimento das cadeiras vagas, segundo um critério de mérito que sobrepujava o da antiguidade e o das graduações ${ }^{46}$. Não deixa de ser pertinente assinalar ainda a criação das categorias de demonstradores e de preparadores, como auxiliares dos professores na execução das experiências e tarefas práticas exigidas pela leccionação das faculdades naturais.

A mais interessante inovação da Reforma, contudo, foi a organização do corpo docente de cada faculdade - lentes proprietários e substitutos, actuais ou jubilados - em Congregações ${ }^{47}$ (formando o conjunto das Congregações

45 Documentos do Reforma, vol. I, doc. $X X X \mid$, pp. 33-42. Com certeza que haviam sido já notadas as dificuldades ocasionadas pelo sistema anterior, uma vez que, por uma provisão de 24 de Maio de 1730, se determinara que os lentes condutários - que auferiam já uma remuneração na Folha da universidade mas que não estavam afectos a nenhuma cadeira particular - fossem os substitutos obrigatórios das cadeiras, devendo também os lentes impedidos escolher entre eles os que os deviam substituir. Permaneciam, contudo - e quando os havia - como substitutos generalistas, e continuaram a ser correntes as substituiçōes feitas pelos lentes das caderras imediatamente inferiores.

46 Decreto de 1 I de Setembro de 1772 (Documentos da Reforma, vol. I, doc. IX, p.1I). Será interessante atentar no texto deste decreto: "sou servido declarar [...] que o mayor direito às Cadeiras vagas, não se entenda deferido aos Cathedraticos, ainda que a ellas pareçam como taes immediatos; mas sim se entenda, que a ellas tem igual Direito os Substitutos para haverem sempre de ser providas as Cadeiras não pellas antiguidades, nem pellas graduaçoens: mas segundo os talentos, genios, e Letras dos Oppozitores, que mais accomodados forem ás disciplinas de cada huma das Cadeiras: De maneira que possa qualquer dos Substitutos subir sem ser gradualmente às Primeiras Cadeiras da sua respectiva Faculdade: sem que por isso se entendam preteridos os Cathedraticos". É evidente que, para além dos "talentos e genios" se atende aqui à especialidade das cadeiras, para as quais podia um substituto ter uma preparação mais "acomodada".

47 A desıgnação, significando o conjunto dos professores de uma facuidade, já se encontra nos Estatutos Velhos embora com um sentido e um alcance bastante diferente do que the é atribuído pela Reforma, conforme se verá. 
das faculdades naturais uma só Congregação Geral). Sintetizando o conjunto de atribuições que thes são confiadas, os Estatutos estabelecem que thes "ficará pertencendo inteiramente o governo e inspecção de tudo o que respeita ao formal e scientifico $[\ldots]$ " 48. No formal - mais ligado a tarefas de organização das actividades lectivas e, sobretudo, dos momentos de avaliação - assumia deste modo a Congregação os papéis que antes eram desempenhados quer pelo Conselho de Conselheiros - no qual não participavam professores - quer pelas anteriores Congregações.

Mas é a responsabilidade cientifica que importa pôr em destaque: as avaliações prospectiva e retrospectiva do estado da faculdade feitas no inicio e no final de cada ano lectivo; o cuidado de vigiar para que se cumprissem, nos conteúdos e nos métodos, as prescriçōes dos Estatutos; o exame dos livros e compêndios que deveriam ser utilizados; o fomento e orientação da feitura dos que de novo se deveriam adoptar; o zelo do contínuo aperfeiçoamento do ensino, pela atenção ao que de novo surgisse, também nos países estrangeiros, e pela adopção do que melhor servisse para o cultivo das ciências professadas.

Particular atenção merece o que se determinava para a o Conselho Médico ou Congregação da Faculdade de Medicina, à qual, para além das incumbências que as outras detinham, competia a inspecção do hospital e a arrecadação das suas rendas, assim como a visita do teatro anatómico e do dispensatório farmacêutico, e também a elaboração de uma "Pharmacopéa Geral do Reino" que servisse de padrão para aferir a prática dos boticários e à qual estes se deviam cingir. Esta extensão de autoridade para além dos muros da Universidade fica ainda mais evidente pela competência conferida à mesma Congregação para impedir que a arte de curar continuasse a ser exercitada por "pessoas idiotas", derrogando-se todos os alvarás e provisões que autorizavam o Físico-Mor e o Cirurgião-Mor a conceder licenças para esse efeito (exceptuando-se apenas os médicos e cirurgiōes formados por universidades estrangeiras que já as tivessem obtido, assim como os cirurgiões 64 vulgares, nos limites que thes tivessem sido fixados).

Poder-se-á sem receio afirmar que se tratava de uma recondução do professor ao cerne do seu múnus. O princípio formulado ainda a propósito

48 Esta formulação encontra-se no liv. I (Teologia). tit VI. cap. I. § 21. Mas estende-se às outras faculdades ( $c$ r., por exemplo, o liv. II, tít XIV, I, onde se fala em um conselho para cada uma das faculdades de Direito, "que tenha a Inspecção, e Intendencia privativa sobre o Formal e Soientifico"). 
da Medicina - a concepção de que o mestre deverá ser não apenas um transmissor de conhecimentos mas também inventor; a injunção de que as novas descobertas fossem de imediato incorporadas no ensino; a ideia de que o progresso da ciência se obtém pela agregação de múltiplos esforços e contributos, também os dos próprios estudantes 49 - dá-nos conta do essencial da expectativa acerca do que deveria ser o professor.

Importava, por isso, libertá-lo de tarefas que o divertissem. Assim se compreende a reformulação da administração da universidade, nomeadamente no que dizia respeito à sua gestão material. Esta cabia anteriormente à Mesa da Fazenda, constituída por quatro deputados grandes, quer dizer, por um grupo de lentes das cadeiras mais importantes (um de cada faculdade). E se já normalmente as suas atribuições eram numerosas e absorventes, mais complexas se tornaram quando (1720), na sequência da falência de dois prebendeiros, a Mesa assumiu as tarefas que a eles competiam ${ }^{50}$. Por alvará de 28 de Agosto de 1772 são cassados e extintos todos os "empregos e incumbencias" de que se compunha a Mesa da Fazenda da universidade. Em sua substituição era criada uma Junta de Administração: dela já não faziam parte professores mas, sob a presidência do Reitor, era constituida por três colegiais opositores, um de cada um dos colégios de S. Pedro, de S. Paulo e dos Militares, escolhidos pelas respectivas capelas ${ }^{51}$. Aos professores ficava agora apenas o encargo, muito menor, da administração da arca das respectivas faculdades.

No que respeita à remuneração dos lentes, as mudanças não terão sido tão assinaláveis como o simples exame dos montantes dos ordenados poderia fazer supor. Tratou-se realmente sobretudo de neles incorporar emolumentos antes recebidos autonomamente, tais como as propinas - que não

49 Estatutos. liv. III. parte I. tít. VII, cap. I, § 6: "E como os Deputados da Congregação da Faculdade são também os principaes Deputados da dita Congregação Geral [das Ciências]; terāo grande cuidado em procurar que nas Lçōes das Aulas se sigam exactamente os passos. e progressos, que a Medicina fizer pelo trabalho, e industria da mesma Congregação Geral destinada a cuidar no adiantamento das Sciencias Naturaes. [...] De sorte que os Ouvintes se utilizem não somente das Liçōes positivas do Mestre, mas tambem das idéas originaes do Inventor; e se ponham no caminho de trabalhar utilmente no adiantamento desta Sciencia, a qual se não pode aperfeiçoar, senão pelos esforços reunidos de muitos engenhos. que cooperam para o bem comum".

50 Fernando Taveira da Fonseca, A universidade de Coimbra, pp. 679-690.

51 Mário Alberto Nunes Costa. Documentos. vol. II. doc. DLXXII. pp. 275-279. 
eram registadas na contabilidade da Mesa da Fazenda, passando directamente das mãos dos bedéis, em cujos róis ficavam anotadas, para as dos lentes o que reduz em muito o alcance do aumento promulgado pelo Marquês de Pombal ${ }^{52}$. E não poderemos dissociar este do de 1754 - suscitado por uma petição dos lentes em 1750 - que se saldou em um terço a mais para todas as cadeiras.

Não há dúvida, porém, que se operava uma certa viragem na filosofia do financiamento da actividade docente: as propinas que os estudantes pagavam. antes da Reforma, destinavam-se apenas a remunerar os intervenientes nos actos e na colação dos graus, sendo irrisória a que deveriam satisfazer no momento de matrícula, ficando deste modo a sua aprendizagem praticamente liberta de encargos. Agora, os estudantes deverão pagar em cada ano 12.800 réis "para a Arca da Faculdade, e subsidio das grandes e extraordinarias despesas que se hão de fazer annualmente, para se poder sustentar e entreter - grande numero de Cathedraticos, Lentes, Substitutos e mais Officiaes, que indispensavelmente deve haver" 53 . É evidente que se aumentavam os encargos dos estudantes 54 e que esta deslocação do momento da satisfação das propinas se transformava em contributo formal para o financiamento da aprendizagem. O Marquês de Pombal afirma-o explicitamente: "o que sei de certo he que os Ordenados que deixei estabelecidos foram arbitrados com a consideração de ficarem abollidas aquellas antecedentes bagatellas depois

52 A mera consideração dos montantes de ordenados fixados estatutariamente é insuficiente para aferır das efectivas remuneraçōes dos lentes. É por isso que não é aceitável a afirmaçāo de que a tabela de ordenados da Reforma representou um "aumento do dôbro, conta redonda" ou que as cadeiras de menor graduação das facuidades juridicas teriam agora "um ordenado triplicado" (vide Dr. Manuel Gonçalves Cerejeira. Notos históncas sobbre os ordenados dos lentes da Universidode, Coimbra, 1927. p. 44). No periodo anterior à Reforma, precisamente nas cadeıras de menor graduação das faculdades juridicas, o montante das propınas superava largamente o dos ordenados: a título de exemplo, refira-se que o lente da segunda catedrilha de Cânones, que auferia 120.000 réis de ordenado, recebeu, no cinco anos entre 1756-57 e 1760-61, um montante médıo anual de 268.000 réis, ou seja, mais do dobro do que the coube pela Folha (vide Fernando Taveira da Fonseca, A Universidade de Coimbra. pp. 483-499 e quadros A. IX. 2. b-e, no Apêndice).

53 Estatutos, liv. II, tít. I. cap. IV. § II.

54 Em média, entre 1725 (anos em que foram aumentadas as propinas a pagar pelos estudantes nos actos) e 1771. um estudante gastaria em propınas, até se formar, entre vinte e cinco e trinta mil réis: agora. nos cinco anos em que tem de matricular-se até à formatura terá de despender 64.000 réis. 
de se acumular ao acrescentamento dos ditos ordenados o encargo dos doze mil e oitocentos reis das Matriculas" 55 .

A contrapartida desta nova filosofia era, para os professores, a de ficarem independentes da conjuntura das graduaçōes, recebendo uma remuneração fixa fosse qual fosse o número de candidatos que se apresentassem a exame. Salvaguardava-se assim a sua posição face às consequências que o carácter mais restritivo do acesso aos estudos universitários pudessem acarretar consigo - como de facto aconteceu, diminuindo drasticamente a população estudantil. Mas permaneciam nos seus ordenados os vestigios das antigas propinas: só assim se explica que cadeiras de igual graduação (que anteriormente à Reforma auferiam iguais ordenados) apresentassem agora tão notáveis discrepâncias, segundo as faculdades (a mais elevada remuneração é, em Teologia, de 480.000 réis, contra os 600.000 réis Medicina e os 800.000 réis em Cânones e Leis).

5. No contexto do reformismo pombalino, as mudanças operadas na Universidade de Coimbra representaram um ponto de chegada e um momento de fixação normativa de um paradigma que se pretendia matricial e modelador do todo social no seu conjunto. Não será, por isso, de estranhar que a contestação à pessoa e à obra do Marquês que se seguiu à sua desgraça política se tivesse também feito sentir neste domínio. Nesse momento crucial terá sido de vital importância a apologia da Reforma feita por D. Francisco de Lemos na sua Relaçāo Geral: o Reitor, formado segundo o modelo antecedente, candidato a uma posição de professor nos concursos de 1765 e, depois, membro destacado da Junta de Providência Literária, conhecia bem as duas faces da situação e explora eficazmente os contrastes entre elas. Teremos, contudo, de pôr o acento principal em todo o processo de consolidação que complementou aquele primeiro momento fundacional e que continuou a ter como protagonista o Marquês de Pombal: uma activa correspondência com o Reitor revela a sua atenção e interesse quer se tratasse das obras que foi necessário efectuar para adaptar os edifícios, dos compêndios e textos a adoptar, do apetrechamento dos gabinetes e laboratórios, quer de problemas disciplinares ou de gestão corrente que importava solucionar. E não dei-

5s Carta do Marquês de Pombal a D. Francisco de Lemos, de 15 de Julho de 1773 , Documentos da Reforma, vol. I, doc. LVIII. p. 92. 
xou o Marquês, tal como o monarca fundador ou como D. joāo III, de compreender que o florescimento da ciência e o labor intelectual exigem a segurança de uma sólida base material que os possibilitem. A doação à universidade dos bens que haviam pertencido aos jesuitas, de 4 de Julho de 1774 - a qual quase duplicava os rendimentos auferidos até aí - tinha de ser atribuída ao monarca, D. José. Mas o Marquês não se exime, ele próprio, de reivindicar a sua quota parte. Em ofício a D. Francisco de Lemos, de 28 de Julho de 1775, acompanhando o envio da sentença apostólica que sancionava a doação feita, afirma de si mesmo aquilo que poderemos considerar como a definição da sua atitude geral: "pelas sentenças, que com esta serão, e que passo às Maons de V. Ex. a verá bem o efficaz cuidado que ponho em tudo o que he util, e decorozo a essa lliustre Universidade" 56. 